\section{Prossumidores e influenciadores no ambiente digital}

\section{Prossums and influences in the digital environment}

Draucio Carvalho dos Santos ${ }^{1}$

\begin{abstract}
Resumo
Este estudo discute a racionalidade do consumidor questionando até que ponto o consumo trata-se de um fenômeno consciente ou o resultado de uma série de fatores. Além de tratar sobre os líderes de opinião e os prossumidores. Ponderando sobre o novo perfil do consumidor. Perfil esse, onde consumidores deixaram a passividade para tornarem-se figuras ativas na influência de outros consumidores tacitamente através de comentários, avaliações de usuários, propaganda boca a boca no ambiente virtual, etc.
\end{abstract}

Palavras-chave: Prossumidores, influenciadores, comportamento do consumidor, líderes de opinião.

\begin{abstract}
This study discusses the rationality of the consumer questioning to what extent consumption is a conscious phenomenon or the result of a series of factors. In addition to dealing with opinion leaders and prosumers. Pondering about the new consumer profile. Profile that, where consumers have left the passivity to become active figures in the influence of other consumers tacitly through comments, user reviews, word of mouth advertising in the virtual environment, etc.
\end{abstract}

Keywords: Prosumers. influencers. consumer behavior. opinion leaders.

\footnotetext{
${ }^{1}$ MBA em Marketing em vendas e pós em Gestão de Mídias Digitais. draucio.carvalho@gmail.com
}

Artigo recebido em: 20 de dezembro de 2018. Artigo aceito em 05 de dezembro de 2020. 


\section{Introdução}

Este trabalho tem por objetivo realizar uma revisão da literatura sobre os prossumidores, a racionalidade dos consumidores e os líderes de opinião (usuários com uma habilidade acima da média para influenciar) através do método de pesquisa documental bibliográfico demonstrando que o consumidor em si, não é um ser racional. E, além disso, é um individuo altamente influenciável.

Demonstrando como o marketing pode influenciar (e influencia) o comportamento de compra dos indivíduos sob a égide do estudo desse comportamento como um fenômeno das influências desses novos consumidores: os prossumidores. Em outros consumidores

Para isso, faz-se necessário realizar uma pesquisa bibliográfica com o intuito de fazer uma revisão da literatura sobre o comportamento refinando o problema, e das respostas desses problemas fazer florescer novas perguntas, indagações, suposições, probabilidades até chegarmos ao perfil dos novos consumidores e sobre os prossumidores. Afinal, na medida em que as mídias sociais tornarem-se mais expressivas, os consumidores, cada vez mais, influenciam outros consumidores com suas opiniões e experiências. E, "este novo perfil de consumidor que não consome passivamente produtos, serviços e opiniões. Ainda é pouco explorado pelos pesquisadores no Brasil” (MOTTA, 2014 p. 19)

Para compreendermos o perfil do novo consumidor, temos que primeiro tratar do perfil do antigo. E, não somente do perfil do antigo consumidor, como do seu comportamento. Dito isso, discorreremos sobre a concepção de sociedade de massas e consumo de massas, ou seja, uma sociedade “(...) na qual as desigualdades sociais geram formas diferenciadas de consumo. Na sociedade de massas, o nivelamento do consumo e dos modos de pensar resultaria da ação dos meios de comunicação de massa" (SANDRONI, 1999, p. 571). Logo, televisão, rádio, jornais, etc. Marcio Serelle num artigo sobre a televisão como meio híbrido no pensamento menciona quê:

A idéia de um consumo social geral, que marcará a segunda metade do século XX, é outro aspecto de hibridação da televisão, que, como forma cultural, herdou tipos de atividades culturais e sociais, adaptados e desenvolvidos na programação, juntamente com formas mistas e inovadoras. (SERELLE, 2016, p. 190)

E Anderson (2006) apresenta o meio social que os indivíduos estavam encapsulados nesse período. Ou seja, uma época que a cultura de massa era maistream. A época onde a oferta era escassa, época onde indivíduos possuíam acesso há um 
número reduzido de canais de TV e concomitantemente tinham acesso aos mesmos programas, época onde estações de rádio impunham boa parte das músicas. E, todos assistiam aos mesmos filmes de sucesso nos cinemas, além de todos receberem suas notícias pelos mesmos jornais e noticiários. Kotler, Kartajaya e Setiawan (2010) denominam isso de marketing 1.0 um marketing com foco em vender os produtos da fábrica a todos que quisessem comprá-los. Por esse aspecto os produtos eram relativamente básicos, pois eram concebidos para servir ao mercado de massa. O objetivo era a padronização e o ganho em escala, reduzindo ao máximo os custos de produção, para que essas mercadorias fossem adquiridas por um número maior de compradores.

Em contraste com essa visão temos uma concepção atual. Onde o comportamento do consumidor abarca o estudo de todo o processo envolvido no momento que indivíduos e (ou) grupos compram ou selecionam produtos, serviços, ideias ou experiências na satisfação de suas necessidades e desejos (KOTLER, 2005). Dessa forma o consumidor assume uma variedade de formas e entendemos que "(...) do ponto de vista social, as etapas do ciclo de vida de um indivíduo marcam a sua preparação para assumir papéis sociais e institucionais" (SANDRONI, 1999, p. 96). Ou seja, os consumidores são atores no palco do consumo. Algo que Solomon fala com propriedade:

A perspectiva da teoria dos papéis vê grande parte do comportamento do consumidor como atos de uma peça. Como no teatro, cada consumidor tem falas, acessórios e figurinos necessários para um bom desempenho da encenação. Como as pessoas representam muitos papéis diferentes, elas às vezes modificam suas decisões de consumo, dependendo da peça específica de que participam em certo momento. Os critérios que usam para avaliar produtos e serviços em um papel podem ser bem diferentes dos utilizados em outro. (SOLOMON, 2006, p. 24)

E isso se deve ao advento da era da informação (e da internet), era onde os consumidores são bem informados e podem facilmente comparar ofertas de produtos semelhantes. Na era da informação a internet é “capaz de levar um milhão de programas para cada pessoa" (ANDERSON, 2006, p. 10). E, diferente do paradigma do consumo de massa que servia a mesma coisa para milhões de pessoas temos hoje consumidores que exigem cada vez mais opções. "A era do tamanho único está chegando ao fim e em seu lugar está surgindo algo novo, o mercado de variedades" (ANDERSON, 2006, p. 10). Mercado esse, onde consumidores e produtores são reunidos eletronicamente duma 
forma nunca vista antes, e agora compartilhamos opiniões, damos curtidas, vemos filmes (streaming), e reunimo-nos em comunidades eletrônicas. Veja o que Kotler, Kartajaya e Setiawan (2010) dizem sobre isso:

Desde o início do ano 2000, a tecnologia da informação penetrou o mercado mainstream, transformando-se no que consideramos hoje a nova onda de tecnologia. Essa nova onda abrange uma tecnologia que permite a conectividade e a interatividade entre indivíduos e grupos. (KOTLER, KARTAJAYA e SETIAWAN, 2010, p. 18)

Diferente do consumo de massa, a era da informação concede aos clientes o acesso a informação. "A informação pode ser infinitamente diferenciada, analisada, personalizada e (...) enviada para muitas pessoas em um curto período de tempo. Com a informação acessível e pública (...) consumidores (...) podem ficar mais bem informados e fazer melhores escolhas" (KOTLER, 2005, p. 2). Tal fato concedeu uma série de vantagens atrativas para os consumidores como: aumento no poder de compra, uma variedade (maior) de bens e serviços disponíveis, uma quantidade infinita de informações sobre diversos bens e serviços, uma maior interação com as empresas e capacidade de comparar impressões sobre produtos e serviços.

\section{Racionalidade do consumidor}

Algumas vertentes identificam o consumidor como um ser racional na tomada de decisão, como uma teoria econômica (especificamente, a Teoria da Demanda do consumidor), que identifica as pessoas como indivíduos calmos e parcimoniosos que ponderam com o máximo de informação sobre o produto ou serviço na tomada de decisão. Segundo essa teoria, "parte-se do pressuposto que os consumidores agem racionalmente e de acordo com axiomas os quais, combinados, constituem uma teoria (verificável) do comportamento do consumidor" (SANDRONI, 1999, p. 37). Ou seja, esmeradamente ponderamos e nos debruçamos sobre os pontos fortes e fracos no momento de tomarmos uma decisão de compra.

Mas diferente dessa teoria, podemos concluir que não somos tão racionais assim. Tanto que, "alguns cientistas estimam que só temos consciência de cerca de $5 \%$ de nossa função cognitiva. Os outros $95 \%$ vão para além da nossa consciência e exercem enorme influência em nossa vida - começando por torná-la possível”. (MLODINOW, 2013, p. 31). Na realidade segundo Solomon (2006) o consumidor avalia todo esforço 
necessário para fazer uma determinada escolha e então opta pela estratégia mais adequada ao nível de esforço exigido. Algo que Kahneman reitera:

Uma lei do menor esforço geral se aplica tanto ao esforço cognitivo quanto ao físico. Essa lei determina que se há vários modos de atingir um mesmo objetivo, as pessoas acabarão por tender ao curso de ação menos exigente. $\mathrm{Na}$ economia da ação, esforço é um custo, e a aquisição de habilidade é impulsionada pelo equilíbrio de benefícios e custos (GUIRE, et al., 2011. Apud, KAHNEMAN, 2012 p. 48)

Dessa forma o estudo do comportamento do individuo no ato de consumir, possui uma importância impar. Afinal, compreender como, e por que os consumidores compram ou utilizam produtos ou serviços, permite ao marketing assimilar o que pode gerar valor para os clientes. Tomando como premissa que valor é a relação entre o custo e a capacidade de determinados produtos ou serviços em satisfazê-las (benefício), podemos chegar à conclusão que somos movidos e pautados pela busca de uma maior quantidade de benefícios: prazer, satisfação. Ao menor custo possível: desconforto, sofrimento (KOTLER, 2005). Desta maneira o viés que deve permear o estudo do comportamento de compra do consumidor deve girar em torno dos processos cognitivos, motivacionais e emocionais que antecedem e sucedem a obtenção, o consumo e a disposição de bens tangíveis e intangíveis, produtos ou serviços (PINHEIRO, CASTRO, et al., 2006).

Por esse aspecto notamos que, primeiro: algumas decisões de compra são tomadas sob baixíssimas condições de atenção. Afinal, "uma concentração profunda faz o consumo de energia do cérebro ter um aumento de cerca de 1\%". (MLODINOW, 2013, p. 32). E somos naturalmente hedonistas no que se refere a consumo de energia (cerebral) um "fenômeno atual do consumismo, frequentemente acompanhado de certa preguiça intelectual e moral" (JAPIASSÚ e MARCONDES, 2001, p. 90). Algo chancelado por Mlodinow e Solomon respectivamente, veja o que ambos dizem: “Os seres humanos também desempenham inúmeros comportamentos automáticos, inconscientes, mas tendem a não perceber isso porque a interação entre nossa mente inconsciente e a consciente é muito complexa”. (MLODINOW, 2013, p. 13)

"Muitas decisões de compra estão tão integradas na rotina que podemos não perceber que as tomamos (...). As escolhas caracterizadas pela automaticidade são realizadas com esforço mínimo e sem controle consciente" (ALBA, et al., 1988. APUD, Solomon, 2006 p. 211)

Segundo, "nosso passado, nossa educação e nossa situação social determinam 
aquilo que acreditamos ser nossas escolhas" (JAPIASSÚ e MARCONDES, 2001, p. 52). "Um artigo publicado por um pesquisador da Duke University em 2006 descobriu que mais de $40 \%$ das ações que as pessoas realizavam todos os dias não eram decisões de fato, mas sim hábitos" (VERPLANKEN, et al., 2006. Apud, DUHIGG, 2012 p. 16)

A maioria das escolhas que fazemos a cada dia pode parecer fruto de decisões tomadas com bastante consideração, porém não é. Elas são hábitos. E embora cada hábito signifique relativamente pouco por si só, ao longo do tempo, as refeições que pedimos, o que dizemos a nossos filhos toda noite, se poupamos ou gastamos dinheiro, com que frequência fazemos exercícios, e o modo como organizamos nossos pensamentos e rotinas de trabalho têm impactos enormes na nossa saúde, produtividade, segurança financeira e felicidade. (DUHIGG, 2012, p. 16)

Logo, seja bom ou ruim, estamos todos encapsulados num mundo significativamente influenciado pelas ações dos profissionais de marketing. Afinal, os estímulos que nos rodeiam são frutos de comerciais, lojas, banners e diversos cartazes disputando nossa atenção (SOLOMON, 2006), abrindo espaço para concluirmos que o marketing impacta diretamente a cultura contemporânea, como registram Orsi, Cappellozza e Vieira (2018). O conceito de Infraestrutura e superestrutura de Karl Marx. Que nos diz que "as forças materiais (especialmente econômicas) dominam e dão forma às forças espirituais, no caso: pensamentos, ideias, políticas, religião, arte, etc." (JAPIASSÚ e MARCONDES, 2001, p. 94). Por esse aspecto compreendemos o quanto Kotler estava correto em sua afirmação: “(...). os desejos são moldados pela sociedade em que se vive, e as demandas são desejos por produtos específicos apoiados pela possibilidade de pagar por eles" (2005 p. 8).

Devido à complexidade do comportamento do consumidor podemos nortear as decisões de compra por um modelo proposta por Solomon (2006), modelo esse também chancelado por Kotler (2005). Nota-se pela figura 1, um fluxograma. Neste modelo o individuo identifica um problema, por exemplo: preciso de um sapato, uma camisa, um carro, uma TV, etc. Após essa identificação pesquisa-se sobre a coisa desejada. Buscam-se alternativas, seja: modelo, cor, especificidades, etc. Daí escolhe-se o produto (compra-se o produto) e posteriormente mensuram-se os resultados da compra (satisfação). E, tudo é diretamente influenciado ou resultado direto de ações do marketing, comunicação e propaganda

Figura 1 - Fluxograma

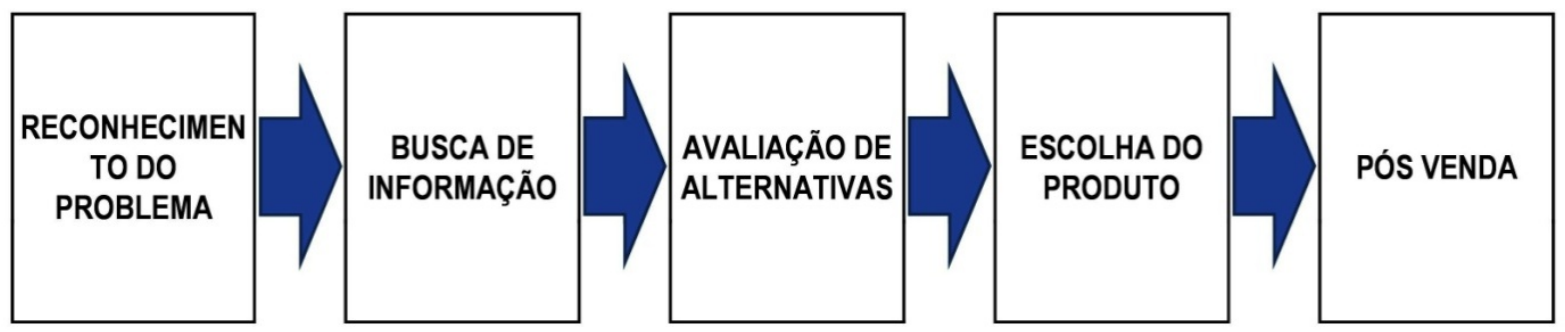


SOLOMON, 2006 p. 209, Adaptado pelo autor

Trataremos cada um dos estágios proposta na figura iniciando pelo: reconhecimento do problema. Os indivíduos possuem necessidades há qualquer momento da vida: fisiológicas, psicológicas, etc. Essas necessidades segundo Kotler (2005) nascem da inquietação inerentes a cada indivíduos. Sendo que, "uma necessidade passa a ser um motivo quando alcança um determinado nível de intensidade. Um motivo é uma necessidade suficientemente forte para levar a pessoa a agir". Solomon (2006) segue uma linha próxima: “o reconhecimento do problema ocorre toda vez que o consumidor vê uma diferença significativa entre seu estado atual e algum estado desejado ou ideal"

O processo de compra começa quando o comprador reconhece um problema ou uma necessidade. A necessidade pode ser provocada por estímulos internos (como fome e sede) ou externos (como ver um anúncio) que se tornam um impulso. Coletando informações junto a vários consumidores, os profissionais de marketing podem indentificar os estímuls mais frequentes que suscitam interesse por uma categoria de produto. A partir disso, podem desenvolver estratégias de marketing que provoquem o interesse do consumidor e o levem a segunda etapa do processo de compra (KOTLER, 2005, p. 133)

"Embora o reconhecimento de um problema possa ocorrer e realmente ocorre de um modo natural, o processo muitas vezes é acionado pelos esforços do marketing" (SOLOMON, 2006, p. 212). Passamos para busca de informações após o reconhecimento do problema, afinal, todo consumidor demanda informações adequadas na resolução do problema reconhecido. Em geral, um consumidor mesmo que conhecedor do mercado precisa complementar seu conhecimento com informações obtidas a partir de comerciais, amigos, observação de outros consumidores e a internet (SOLOMON, 2006). Esse paradigma é chancelado por Kotler, segundo ele: "Na busca ativa de informações a pessoa navega na internet conversa com os amigos e visita lojas online para saber mais sobre o produto”. (KOTLER, 2005, p. 133). Na avaliação das alternativas, já vimos que o consumidor não é um ser racional, calmo e parcimonioso que pondera com o máximo de informação sobre o produto ou serviço no momento da 
escolha, na realidade sofremos influências de uma série de fatores que transcendem nossa consciência, por exemplo:

No estudo relacionado aos detergentes, os participantes receberam três diferentes caixas de detergente; foi pedido que experimentassem todos por algumas semanas e depois dissessem de qual tinham gostado mais e por quê. Uma das caixas era predominantemente amarela, outra azul, a terceira azul salpicada de amarelo. Em suas respostas, os sujeitos mostraram grande preferência pelo detergente na caixa de duas cores. As razões incluíram muitos méritos relativos dos detergentes, mas ninguém mencionou a caixa. Por que mencionariam? Uma embalagem mais bonita não faz com que o detergente funcione melhor. Mas na verdade a diferença estava na caixa - pois os produtos eram idênticos (HIRSHLEITER e SHUMWAY, 2003. Apud, MLODINOW, 2013, p. 22)

Após o cliente reconhecer o problema, buscar informações e avaliar as alternativas temos como resultado: a compra. Ou seja, a escolha do produto e essa escolha acima de tudo deve ser uma experiência de compra, afinal, a compra é uma forma de adquirir produtos e serviços, mas no marketing o foco repousa nos motivos que levam indivíduos a comprar. E, esses motivos são estimulados pela experiência de compra, ou seja, "o conjunto das percepções que um consumidor desenvolve ao interagir com uma loja durante as fases de pesquisa, compra e até a relação pós-venda" (SEBRAE, 2017). Dessa forma, “comprar é uma atividade que pode ser desempenhada tanto por razões utilitárias (funcionais ou tangíveis) quanto por razões hedônicas (prazerosas ou intangíveis)" (SOLOMON, 2006, p. 238).

Como última etapa temos o comportamento do consumidor pós compra onde se deve mensurar os níveis de satisfação e insatisfação dos clientes.

A satisfação do consumidor é determinada pelo sentimento global da pessoa em relação ao produto depois da compra. Muitos fatores influenciam as percepções da qualidade do produto, incluindo o preço, o nome da marca e o desempenho do produto. A satisfação com frequência é determinada pelo quanto o desempenho de um produto é coerente com as expectativas prévias do consumidor (SOLOMON, 2006, p. 251)

A satisfação do cliente após a compra influenciará no seu comportamento posterior. Se as expectativas do comprador forem atendidas ou não, determinará se o cliente falará bem ou mal do produto a outras pessoas. "Os clientes satisfeitos tendem a dizer coisas boas sobre a marca para outras pessoas" (KOTLER, 2005, p. 137). Dado a importância da influencia dos consumidores em outros consumidores temos que entender que "os novos formadores de preferências somos nós. Agora, a propaganda boca- 
a-boca é uma conversa pública, que se desenvolve nos comentários de blogs e nas resenhas de clientes, comparadas e avaliadas de maneira exaustiva". (ANDERSON, 2006, p. 89).

Conversas espontâneas sobre marcas possuem mais credibilidade do que campanhas publicitárias voltadas para um público específico. Círculos sociais tornaram-se a principal fonte de influência, superando as comunicações de marketing e até as preferências pessoais. Os consumidores tendem a seguir a liderança de seus pares ao decidir qual marca escolher. É como se estivessem se protegendo de alegações falsas das marcas ou de campanhas publicitárias ardilosas e usando seus círculos sociais para construir uma fortaleza. (KOTLER, KARTAJAYA e SETIAWAN, 2017, p. 18)

Dessa forma "os novos formadores de preferências são simplesmente pessoas cujas opiniões são respeitadas. Elas influenciam o comportamento de outras, quase sempre as encorajando a tentar novas coisas que, do contrário, não experimentariam" (ANDERSON, 2006, p. 97)

\section{Prossumidores}

Segundo Motta (2014) em seu artigo como mestranda em Ciências da Comunicação podemos definir prossumidores como: "cliente que troca informações não só com a empresa diretamente, mas com todos aqueles que quiserem e tiverem acesso a suas opiniões“. Já Kotler (2005) define prossumidores como aqueles clientes que essencialmente projetam e customizam seus próprios produtos.

Kotler, Kartajaya e Setiawan (2010) mencionam que "os consumidores acreditam mais uns nos outros (...). E que a ascensão das mídias sociais é apenas reflexo da migração da confiança dos consumidores das empresas para outros consumidores”. Logo, concluí-se que a nova onda da tecnologia e ascensão da mídas sociais transforma as pessoas de consumidores em prosumidores.

Por esse aspecto podemos concluir que Prossumidores são indivíduos que consomem, criam, influenciam, ressignificam conteúdo, etc. Claro, tudo ao mesmo tempo. Esses novos sujeitos agem e coexistem no ciberespaço, eles selecionam suas próprias mídias e desenvolvem seu próprio conteúdo. Portanto, os paradigmas tradicionais típicos de uma sociedade de massa, foram deixados para trás. (MORENO e MONTOYA, 2015) corroborando com essa definição Motta (2014) em seu artigo como mestranda em Ciências da Comunicação diz:

Prossumidor é inegavelmente um grande consumidor, um ditador de tendências de consumo que está credenciado pelas tecnologias atuais 


\section{SANTOS}

(...). Participa indiretamente e diretamente dos processos de criação e redesenho no comportamento, em outras palavras: é um influenciador (DAGUILA., s.d.Apud, MOTTA, 2014, p. 33)

\section{Influenciadores no ambiente digital}

Como já mencionado: um Prossumidor é um influenciador (MOTTA, 2014). Dessa forma com expansão da tecnologia da informação a internet tornou-se um ambiente atrativo para pessoas e empresas. Por esse aspecto, a rede de internet e concomitantemente as redes sociais perdem o propósito de servirem apenas como forma de entretenimento, e transformam-se numa plataforma para consumidores realizarem trocas de experiências e preferências em relação às marcas de consumo (NUNES, FERREIRA, et al., 2018). Essa perspectiva é reiterada por Kotler que nos diz:
À medida que as mídias sociais se tornarem cada vez mais expressivas, os consumidores poderão, cada vez mais, influenciar outros consumidores com suas opiniões e experiências. A influência que a propaganda corporativa tem em moldar o comportamento de compra diminuirá proporcionalmente (KOTLER, KARTAJAYA e SETIAWAN, 2010, p. 19)

Notamos a importância das avaliações de usuários na internet como uma propaganda boca a boca virtual, e uma importante fonte de informação para a tomada de decisão de outros consumidores (NUNES, FERREIRA, et al., 2018). Isso somado ao que Kotler (2005) nos diz; descortina a importância dos influenciadores no ambiente digital. Segundo ele, um cliente satisfeito permanece fiel, adquire mais produtos, fala bem da empresa e de seus produtos, disponibiliza uma atenção menor para a concorrência, está menos sucetível a flutuações de preço, dá sugestões para novos produtos e serviços e custam menos para serem atendidos, do que novos clientes, uma vez que suas transações com a empresa tornaram-se rotineiras. E, esses desdobramentos foram maximizados pela expansão da tecnologia da informação, da internet e das redes sociais. Essa linha é reiterada por ANDERSON (2006) que diz: "Os novos formadores de preferências somos nós. Agora, a propaganda boca a boca é uma conversa pública, que se desenvolve nos comentários de blogs e nas resenhas de clientes, comparadas e avaliadas de maneira exaustiva". E por MOTTA (2014), segundo ela prossumidores também são influenciadores que interferem através de opiniões boca a boca na decisão de compra de outros consumidores e nas estratégias mercadológicas das empresas. Dentre os influênciadores temos os líderes de opinião, uma das principais fontes de propaganda 
boca a boca virtual (SHI \& WOJNICKI, 2014. Apud, NUNES, FERREIRA, et al., 2018). Líderes de opinião são indivíduos que têm a capacidade de influenciar pensamentos, atitudes ou comportamentos de outras pessoas para que ajam de um determinado modo, com uma determinada frequência (ROGERS, 1983. Apud, NUNES, FERREIRA, et al., 2018).

Líderes de opinião (...) podem influenciar pessoas de três principais formas: servindo de modelo a ser copiado, fazendo propaganda boca a boca ou dando conselhos de compra e uso (MERWE \& HEERDEN, 2009. Apud, NUNES, FERREIRA, et al., 2018). Dada a importância dos líderes de opinião, profissionais de marketing estão interessados na identificação de pessoas influentes, na verdade, muitos anúncios têm como objetivo atingir esses influenciadores, ao invés do consumidor comum (SOLOMON, 2006).

\section{Analise e discussão dos resultados}

Dentre a bibliografia pesquisada, podemos notar o quanto Kotler, Kartajaya e Setiawan (2010) estavam corretos ao delimitar que o conceito de confiança do consumidor não é mais verticalizado, passando a ser horizontalizado. Ou seja, consumidores que eram facilmente influenciados por campanhas de marketing migraram sua confiança das empresas para outros consumidores, sejam eles: amigos, seguidores, família, do Facebook, do Twitter, etc. Em detrimento das comunicações advindas do marketing. Algo que é plenamente chancelado por Anderson (2006) que utliza uma metáfora para demonstrar esse fato quando menciona que atualmente "formigas têm megafones". Uma clara referência a ascensão dos novos formadores de opinião e influenciadores no ambiente digital, fato esse que também é mencionado por Motta (2014), que denomina tais consumidores que, através de suas opiniões boca-aboca, influenciam outros consumidores de: prossumidores. Denominação essa que é corroborada por: Kotler, Kartajaya e Setiawan (2010), Moreno e Montoya (2015).

Através das contribuições de Kahneman (2012), Kotler (2005), Solomon (2006) e Duhigg (2012) que complementam-se no que tange o comportamento do consumidor, compreender dois pontos: primeiro, o ato de consumo não é um fenômeno racional, pelo contrário, normalmente é resultado de um esforço mínimo com pouca consciência resultado de hábitos de consumo adquiridos pela cultura, família, marketing, etc. E 


\section{SANTOS}

segundo, somos hedonistas em si, daí a economia de energia e esforço mental nas decisões de compra. Fato chancelado por Kahneman (2012) e Mlodinow (2013).

Algo que vai de encontro a ascensão dos prossumidores e líderes de opinião, pois, consumidores corriqueiramente adotam estratégias para reduzir o risco em razão de sua capacidade limitada de processamento mental. A provisão de recomendações ajuda os consumidores na redução da quantidade de informações processadas e filtradas devido grande quantidade de opções de produtos e serviços disponíveis em ambientes de compra virtuais, fato chancelado por Motta (2014), Nunes (2018) e Kahneman (2012).

Dito isso, balizamos o papel do líder de opinião, indíviduos que conhecem um produto e cujas opiniões são consideradas no momento de tomada de decisão por outras pessoas. Neste trabalho o papel dos líderes de opinião foi discutido por Solomon (2006), Kotler e Armstrong (2007) e Nunes (2018) que define um líder de opinião como pessoa que frequentemente é capaz de influenciar atitudes ou comportamento de outras pessoas. E, dessa discussão chegamos em um constructo: na medida que as mídias sociais difundiú-se, nota-se o papel dos consumidores influenciando outros consumidores com suas opiniões e experiências, sendo que, nesse fenômeno destacamse indivíduos tidos como líderes de opiniões. Como resultado desse fato notamos empresas desdobrando-se para manter seus cliente satisfeitos e encantados, pois clientes encantados tornam-se envagelizadores de clientes que contam aos outros, os pontos positivos e negativos de suas experiências de compra (Kotler e Armstrong, 2007)

\section{Considerações Finais}

Este trabalho se propôs a discutir sobre os prossumidores, a racionalidade dos consumidores e os líderes de opinião. Com base na bibliografia apresentada notamos que o fenômeno do consumo, não se trata de um fenômeno racional, pelo contrário, trata-se do resultado de um esforço mínimo com pouca consciência resultado de hábitos de consumo adquiridos pela cultura, família, marketing, etc. Discorremos sobre o novo perfil do consumidor: os prossumidores.

Um perfil que MOTTA (2014) descreveu com perfeição: prossumidor é um consumidor que dita tendências de consumo e participa direta ou indiretamente dos 
processos de criação e redesenho no comportamento do consumidor, ou seja, um influenciador.

Dentre os prossumidores destacamos o papel de alguns usuários com uma habilidade acima da média para influenciar outros, os líderes. Líderes de opinião são indivíduos que têm a capacidade de influenciar pensamentos, atitudes ou comportamentos de outras pessoas para que ajam de um determinado modo, com uma determinada frequência (ROGERS, 1983. Apud, NUNES, FERREIRA, et al., 2018).

Tal discussão contribui na compreensão da forma como outros consumidores e indivíduos influenciam nossas decisões de compra no ambiente digital através da relação entre a expectativa e a experiência de compra em si. Afinal, devido o ambiente social de pouca confiança Kotler e Armstrong afirmam que: "a recomendação de um parente ou amigo aparece no topo da lista em praticamente qualquer levantamento sobre influências de compra". (2007, p. 365), complementado por Motta (2014), Nunes (2018) e Kahneman (2012) que diz: as recomendações ajudam consumidores na redução da quantidade de informações processadas e filtradas devido grande quantidade de opções de produtos e serviços disponíveis em ambientes de compra virtuais.

Quanto à limitação neste trabalho, assume-se a necessidade de uma pesquisa quantitativa a fim de testá-lo e reiterá-lo. No que tange pesquisas futuras recomenda-se estudos sobre os desdobramentos negativos da propaganda boca-a-boca nas redes sociais e impactos de boatos infundados que se difundem nas redes sociais, e o papel do relações públicas nesses pontos supracitados.

\section{Bibliografia}

ANDERSON, C. A cauda Longa: do mercado de massa para o mercado de nicho. Tradução de Afonso Celso da Cunha Serra. Rio de Janeiro: Elsevier, 2006.

DUHIGG, C. O poder do hábito [recurso eletrônico]: por que fazemos o que fazemos na vida e nos negócios. Tradução de Rafael Mantovani. Rio de Janeiro: Objetiva, 2012.

EDUCAÇÃO, H. Palestra de Philip Kotler na HSM Educação. Canal do You tube: EstadãoEdu TV, 27 Junho 2012. Disponivel em:

$<$ https://www.youtube.com/watch?v=pfAYuBV2jhM\&t=13s $>$. Acesso em: 25 Junho 2018.

JAPIASSÚ, H.; MARCONDES, D. Dicionário Básico de Filosofia. Rio de Janeiro: Jorge Zahar Editor, 2001.

KAHNEMAN, D. Rápido e Devagar: duas formas de pensar. Tradução de Cássio de Arantes Leite. Rio de Janeiro: Objetiva, 2012. 
KOTLER, P. Marketing Essencial. Tradução de Sabrina Cairo. São Paulo: Pearson, 2005.

KOTLER, P.; ARMSTRONG, G. Princípios de Marketing. Tradução de Cristina Yamagami. São Paulo: Pearson Prentice Hall, 2007.

KOTLER, P.; KARTAJAYA, H.; SETIAWAN, I. Marketing 3.0: As forças que estão definindo o novo marketing centrado no ser humano. Tradução de Ana Beatriz Rodrigues. Rio de Janeiro: Elsevier Editora ltda, 2010.

KOTLER, P.; KARTAJAYA, H.; SETIAWAN, I. Marketing 4.0. Rio de Janeiro: Sextante, 2017.

MLODINOW, L. Subliminar: Como o inconsciente influencia nossas vidas. Tradução de Claudio Carina. Rio de Janeiro: Zahar, 2013.

MORENO, M. A. Á.; MONTOYA, L. H. B. DOS CIDADÃOS PARA OS PROSUMIDORES, NOVAS REPRESENTAÇÕES E CONSUMO. SCIELO: anagramas rumbos sentidos comun, Medellín, vol.13 no.26, 2015.

MOTTA, B. S. Prossumidores: O novo papel dos consumidores na era da informação e sua influência na decisão de compra, São Paulo, 2014.

NUNES, R. H. et al. Efeitos das recomendações de líderes de opinião em mídias sociais sobre a intenção de compra de seus seguidores. RBGN - Revista Brasileira De Gestão De Negócios, São Paulo, 20, 2018.

ORSI, D. O.; CAPPELLOZZA, A.; VIEIRA, A. Práticas de Consumo Colaborativo na Cidade de São Paulo: Um Estudo nos Estratos Econômicos A e B. Revista de Inovação e Sustentabilidade, v. 9, n. 3, p. 109-121, 2018.

PINHEIRO, R. M. et al. Comportamento do Consumidor e pesquisa de Mercado. Rio de Janeiro: Editora FGV, 2006.

SANDRONI, P. Novíssimo Dicionário De Economia. São Paulo: EDITORA BEST SELLER, 1999.

SEBRAE. O que é a experiência de compra? SEBRAE - Serviço Brasileiro de Apoio às Micro e Pequenas Empresas, 2017. Disponivel em: $<$ http://blog.sebraesc.com.br/o-que-e-experiencia-de-compra/>. Acesso em: 08 Setembro 2018.

SERELLE, M. A televisão como meio híbrido no pensamento de Raymond Williams. Significação, 43, 2016.

SOLOMON, M. R. O Comportamento do Consumidor: comprando, possuindo e

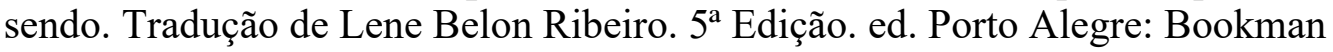
companhia editora, 2006. 